\title{
LA POLÍTICA DEL LÓGOS: REFLEXIONES SOBRE EL PENSAMIENTO POLÍTICO DE HERÁCLITO DE ÉFESO ${ }^{1}$
}

\author{
Sebastián Aguilera Quiroz \\ Pontificia Universidad Católica de Valparaíso. Chile
}

Resumen: La mayoría de los estudios acerca de Heráclito no han dado importancia a un tema evidente en los fragmentos del efesio: La política. En este sentido, proponemos releer los fragmentos, para reconstruir los ejes por los que se movería el pensar político de Heráclito. Al reunir filosofía e historia, podemos ver en el pensamiento de Heráclito cómo la política se nutre de las reflexiones que el filósofo hace de su propia experiencia histórica y cómo estos pensamientos pueden encauzarse dentro de su "sistema" filosófico a partir de la idea de lógos como pensamientos de orden político.

Palabras Clave: Heráclito - política - lógos - nómos - ley - noûs - comunidad

\section{THE POLITICS OF LÓGOS: REFLECTIONS ON THE POLITICAL THOUGHT OF HERACLITUS OF EPHESUS}

\begin{abstract}
Most of the studies on Heraclitus have not given real importance to certain evident matters on the fragments of the Ephesian, especially: the Politics. In this study we propose a new lecture of the fragments that allows us to reconstruct the axes by which the political thought of Heraclitus should have moved. To gather history and philosophy, we can see in Heraclitus's thought how the politics is nurturing by the reflections that the philosopher made about his

\footnotetext{
${ }^{1}$ Este trabajo se enmarca dentro de la investigación de Tesis Doctoral que realizo en el Programa de Doctorado en Filosofía de la Pontificia Universidad Católica de Valparaíso, titulado: "Aproximación al pensamiento de Heráclito de Éfeso: análisis de las relaciones contextuales y de la metafísica religiosa en su filosofía”, dirigido por el Prof. Dr. Héctor Eduardo García Cataldo, a quien aprovecho de dar mi agradecimiento por su inestimable consejo, y que es posible gracias a una Beca CONICYT. El texto aquí presente es una ampliación, con las debidas correcciones de contenido y forma, de la conferencia leída en el III Congreso Internacional de Estudios Griegos, organizado por el Centro de Estudios Griegos Bizantinos y Neohelénicos "Fotios Mallero»", de la Universidad de Chile y el Centro de Estudios Clásicos "Giuseppina Grammático Amari”, de la Universidad Metropolitana de Ciencias de la Educación, en Octubre de 2012.
} 
own historical experience and how those thoughts, within their political sense, can be channeled into the philosophical "system" by the specific notion of logos.

Keywords: Heraclitus - Politics - logos - nómos - Law - noûs - Community

Recibido: 22.01.13 - Aceptado: 18.04.13

Correspondencia: Sebastián Aguilera Quiroz.noncogitoergosum@yahoo.es Licenciado en Filosofía y Educación, Profesor de Filosofía, Dr. Cen Filosofía por la Pontificia Universidad Católica de Valparaíso. Ayudante de Cátedra Griego I en PUCV. Becario CONICYT. Dirección: Avda. El Bosque 1290, Sausalito, Valparaíso.

\section{I: El contexto y los supuestos}

partir de ciertos fragmentos de Heráclito es posible establecer nociones
para desarrollar una "política" heraclítea. Esto tiene dos sentidos: a)
que el alcance de la "política heraclítea" devenga en un cierto modo de obrar político del hombre, no entendido a modo de institucionalidad política formal, sino como la institución del hombre como ser político, es decir, un hombre de la pólis, y b) que la "política heraclítea" sea lo suficientemente clara y coherente, al menos en sus puntos esenciales, como es de esperarse en un autor del mundo griego arcaico, como para hablar seriamente de una filosofía politica heraclítea o, al menos, de una teoría política heraclítea.

Antes de comenzar, es necesario hacer algunas precisiones, de manera sumaria y esquemática, para continuar por "suelo firme" en el camino que nos llevará a la política heraclítea. Werner Jaeger, en el año 1947 escribió su opúsculo Alabanza de la ley: los orígenes de la filosofía del derecho y los griegos, donde realiza un panorama general de cómo los griegos se enfrentaron a los fenómenos de la justicia y del derecho, desde Homero al período helenístico (aunque con más detalle hasta Las leyes de Platón), concluyendo que el hombre griego había mantenido una idea central en sus especulaciones sobre la naturaleza del derecho y la justicia (nociones fundamentales para una teoría política) que se mantuvo casi sin variaciones desde Homero hasta Platón, sobreviviendo a la crisis subjetivista impulsada por sofistas como Protágoras, y que dice relación con un iusnaturalismo fundamental:

"Como se desprende de nuestra visión sinóptica de los esfuerzos de los griegos en este ámbito, el rasgo dominante del pensamiento jurídico griego desde sus comienzos hasta las altas cumbres de la filosofía jurídica consistió en referir la ley y el derecho al ser, es 
decir, a la unidad objetiva del mundo en cuanto cosmos, en cuanto orden ontológico y permanente de cosas que al propio tiempo es el orden ideal de todos los valores y el fundamento de la vida y la libertad del hombre"2.

Entendiendo que, en general, y sentando un supuesto básico en este estudio de la política de Heráclito, el hacer del hombre se relaciona íntimamente con el devenir del mundo, del cosmos. Esta tesis ha sido sostenida por lo estudiosos ${ }^{3}$ no tanto referida a la concepción de una política en Heráclito como referida al principio metafísico, o principio primero ( $\varrho \varrho \chi \eta ́)$ que sostiene todo lo que hay y su íntima relación con el hombre, con el ser del hombre. Vemos también que, en particular, la metafísica heraclítea no puede sino estar, también de manera íntima, ligada a otras especulaciones del filósofo; mejor dicho, una metafísica ${ }^{4}$ implica una teoría política, ética, moral, religiosa, filosófica, antropológica, etcétera, y viceversa.

Veinte años más tarde, Olof Gigon, en su Der Ursprung der griechische Philosophie, entiende a Heráclito principalmente como un ético que exhorta a vivir en conformidad con la verdad y lo enmarca como alguien que se ocupa de los asuntos humanos. Gigon entiende a Heráclito como un moralista 5 , "porque lo que le importa es configurar la acción y, consiguientemente, su verdad tiene forma de ley"6. Idea que actúa en nuestro trabajo como un segundo supuesto: la verdad promulgada por Heráclito, que es la verdad del lógos, no es otra

${ }^{2}$ W. Jaeger 1982; Cf. también P. BisÉ 1925: 65 ss.; O. Gigon 1980: 221.

${ }^{3}$ En el sentido en que aquel principio (lógos, fuego, rayo, guerra, dios, etcétera), al gobernar el mundo en su totalidad tiene que someter de alguna manera también el entendimiento o espíritu humano a obrar de cierta manera. Cf., entre otros, W. Capelle 1981; A. Kostas 1962; W. Jaeger 1982, 2003, 2006; W. K. C. Guthrie 1991; G. Colli 2010: 175 ss; M. Marcovich 20012: 1 ss; H. FrÄNKel 20042: 349 ss. Contrariamente, hay quienes piensan que lógos, por ejemplo, no es ningún principio metafísico, sino el "discurso" filosófico de Heráclito, Cf., M. Conche 1986; CH. KaHn 1979.

${ }^{4}$ Entendemos aquí "metafísica" en sentido amplio: como una explicación coherente del "mundo" o de la "realidad" en que se está, así podemos hablar de una metafísica heraclítea como la exposición acerca de la realidad, o de la constitución o esencia de la realidad, como también de una metafísica de Anaximandro, Anaxímenes, Tales, Pitágoras, el Orfismo, etc... Para no confundirse con la metafísica a partir de Platón y Aristóteles y escapar, en caso de que se pueda, de analizar con criterios ajenos a la Grecia arcaica la misma Grecia arcaica. Al respecto, puede verse M. Heidegger \& E. Fink 1986: c. VI - VII.

${ }^{5}$ Una síntesis y una propuesta de Heráclito como moralista preocupado de enseñar una "vida buena", puede leerse en R. Mondolfo 2007: 328 ss.

${ }^{6}$ O. Gigon 1980: 222. 
cosa que el nexo entre el devenir del mundo y el hacer del hombre que vive en él, es decir, la ley del universo, que Jaeger vio en conexión con la sociedad humana en las especulaciones poéticas y filosóficas de la época arcaica griega, aparece en Heráclito manifestándose como una preocupación por entender el obrar del hombre en conformidad con el devenir del universo. Para Gigon, "a Heráclito no le interesa la construcción de una estructura cósmica visible, sino la demostración de una ley unitaria que rige la vida del cosmos y la acción del hombre: la lucha y la unidad de los opuestos"7. "A él le interesa el obrar del hombre y el mostrar que este obrar está sometido a la misma ley de la lucha

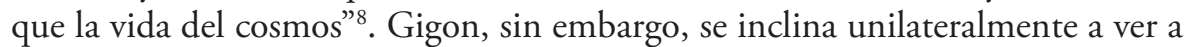
Heráclito como un moralista, opción que nosotros no seguimos?.

Un tercer supuesto lo encontramos en un trabajo reciente (2008) de Raúl Caballero, filólogo clásico de la Universidad deMálaga, España, titulado "Las musas jonias aprenden a escribir: ley escrita y tratado en prosa en los milesios y Heráclito" ${ }^{10}$. En este trabajo, Caballero esboza dos puntos importantes para efectos de nuestra presentación. El primero tiene que ver con el hecho de que Heráclito haya depositado su obra en el templo de Ártemis, acto que simboliza que Heráclito quería que su escrito fuera tan legítimo y valioso como las leyes, que se acostumbraban ofrendar en materiales duraderos como tablillas, o papiro, como en el caso de Heráclito. Por otro lado está el hecho de que Heráclito, según las demostraciones de Caballero, estuvo inclinado a un ideario político representado por su amigo Hermodoro, a quien, como se sabe, expulsaron sus compatriotas efesios, que abrazaban ya la democracia ${ }^{11}$. Veamos brevemente cada uno de estos dos puntos antes de continuar. Caballero parte su ensayo diciendo que:

"En la Jonia del siglo VI a. C., la publicación de los primeros tratados en prosa de los presocráticos obedeció no tanto a la demanda de un público lector, entonces casi inexistente, cuanto a

\footnotetext{
${ }^{7}$ Ibíd.: 272.

${ }^{8}$ Ibíd.: 272.

${ }^{9}$ No lo seguimos en el sentido siguiente: si llamamos a Heráclito "moralista" lo que estamos haciendo, quizá sin querer, es mutilar su pensamiento y reducirlo a esa categoría o a otras, como "naturalista", que más bien sesgan las visones que se intentan de reconstrucción y análisis de un pensamiento tan audaz y original como es el del filósofo de Éfeso. Por ello preferimos, dada la circunstancia, llamarlo simplemente filósofo, como aquel hombre abierto a todos los problemas que el mundo le plantea.

${ }^{10}$ R. Caballero 2008: 1-33.

${ }^{11}$ Her., Historia, VI, 43.
} 
un cierto mimetismo de lo que significaba en las ciudades arcaicas la promulgación y exhibición pública de las leyes"12.

Esta idea es central en el argumento de Caballero, pues de ella deriva que Heráclito, al depositar su libro en el Artemisio, está realizando un gesto tal que confiere valor de ley a su filosofía, dentro de la vida de la polis ${ }^{13}$. Esto puede pensarse si ponemos los ojos, siguiendo a Gigon y Jaeger, entre otros, en que Heráclito relaciona la ley universal que mueve el mundo con la ley o leyes que mueven a los hombres, y su obra no fue meramente un acto despreciativo hacia sus conciudadanos ${ }^{14}$. Sobre esta base, puede decir Caballero que la autonomía del tratado en prosa que Heráclito depositó, concientemente, en el templo de Ártemis, obedece "a su convicción en la naturaleza objetiva y universal (común) del discurso (lógos), cuyo vehículo material era el libro" ${ }^{15}$. En este sentido, Heráclito, depositando el libro, intentó no otra cosa que mostrar la ley universal común a todos, según la cual todos deberían, imperativamente, regirse en sus vidas, tanto individual como social o políticamente.

Lo que nos lleva a la otra parte dela presentación de Caballero: Heráclito habría apoyado una reforma política impulsada por Hermodoro. Esta tesis ya había sido enunciada, aunque no profundamente trabajada, por Miroslav Marcovich, en la década del 70, en su Editio Maior de los fragmentos de Heráclito ${ }^{16}$. Marcovich, al inicio del comentario a su fragmento 105 (22 B121 DK),

12 R. Caballero 2008: 2. Además nos dice que "la fuerza normativa de la ley, la autoridad de sus prescripciones dependían simbólicamente de la visibilidad de los textos legales, que se publicaban, sobre imponentes inscripciones de piedra, en edificios civiles y religiosos de la polis.” Una de las bases de esta idea de Caballero es R. Thomas 1992: 65 ss. En la p. 71, la profesora de Clásicas de Oxford menciona que en cierto periodo, más o menos en el siglo VI, la ley escrita no tuvo tanto valor y tendió a asociarse al ámbito religioso. De ahí que se encuentre una inscripción legal que contiene dentro de sí la alusión al castigo de un dios si se transgrede tal o cual norma. "What is particularly striking is how many laws have religious sanctions, an oath, or a curse in the case of Teos, and several laws are actually dedicated to a god who is to ensure that no one transgresses them: 'May there be destruction on those who transgress it, but may the god (Pythian Apollo) be kind to him who observes it' (ML 13.14-16). These archaic inscriptions are often put up near or on the side of temples. The writing itself was not thought sufficient to make the law secure, and there are attempts to associate the laws with the gods." Ver también J. BREMMER 1994: 32.

${ }^{13}$ R. Caballero 2008: 23. “intentaré mostrar... que Heráclito, al ofrecer su libro a Ártemis, no quería hurtarlo a sus conciudadanos, sino situarlo simbólicamente en el centro de la vida política de Éfeso, como se hacía con las leyes en los espacios públicos de la ciudad”.

${ }^{14}$ Cf., p. e., D. L., Vidas, IX, 1, 3, 6.

${ }^{15}$ Ibíd.: 28.

${ }^{16}$ M. Marcovich $2001^{2}$. 
Sebastián Aguilera Q. : La política del logos: reflexiones sobre el pensamiento político...

dice que "la sentencia está vacía de cualquier sentido filosófico, pero es una pieza maestra como evidencia del punto de vista político de Heráclito" ${ }^{17}$. Esto se entiende por la "reprimenda" que hace Heráclito de suicidio masivo en la horca a sus compatriotas efesios hacia sí mismos, por no haber valorado a quien fuese el más útil varón entre ellos, Hermodoro ${ }^{18}$. Caballero explica con mayor detalle este punto. Los testimonios, que son pocos, hacen pensar en una reforma política que básicamente proponía limitaciones de diverso orden a las clases aristocráticas de Éfeso, acostumbradas ya a la riqueza y ostentación de la misma.

"Esta es la nobleza que ve amenazada su posición dominante por la propuesta legislativa de Hermodoro, con medidas que, por desgracia, se nos escapan en sus pormenores, pero que apuntan a una contención espiritual y material del estilo de vida aristocrático (...) La legislación suntuaria no se agotaba en medidas de contención material, sino que ponía en cuestión el estilo de vida de una aristocracia ávida de extender sus riquezas a costa del pueblo" ${ }^{19}$.

A este respecto pueden agregarse como apoyo numerosos fragmentos y testimonios de Heráclito, sobre la riqueza, la sōphrosýne, la sabiduría, la famosa declinación de arcontado en su ciudad, etcétera, que no hacen sino confirmar en gran medida la afinidad política con la supuesta legislación de Hermodoro. Baste con eso, esquemáticamente, para enunciar el telón de fondo donde se moverá esta exposición. Ahora pasemos a la revisión y análisis de fragmentos.

\section{Los fragmentos}

Miroslav Marcovich ${ }^{20}$ divide su edición de los fragmentos en tres grandes partes: La doctrina del Logos (Frs. 1-50), la doctrina del Fuego (Frs. 51-93) y los fragmentos referentes a Ética, Política y el resto (Frs. 94-12521), que son, estos últimos, los fragmentos que, por distintas razones, Marcovich considera espurios o sospechosos de no ser genuinos ${ }^{22}$. El grupo $23^{23}$, que agrupa los fragmentos

${ }^{17}$ M. Marcovich 2001²: 541, (la traducción es mía). Ver también el comentario de M. Conche 1986: 143 ss (Fr. 37).

${ }^{18}$ Cf., G. Colli 2010: 171.

${ }^{19}$ R. Caballero 2008: 13. Cf. También S. Mazzarino 1989²: 207; A. Capizzi 1979: 47 ss.

${ }^{20} \mathrm{Cf}$., para un comentario genérico de la obra y proyectos inconclusos de Marcovich: R. Mondolfo 2007: 90.

${ }^{21}$ Parte dentro de la cual, los fragmentos 112-125, esto es, en la edición DK: B115, B47, B46, B67a, A16, B126a, B127, B132, B133, B134, B135, B130 y B138, son considerados dubia et spuria. 
DK B 43, B 44, B 33, B 121 y B 125a, trata exclusivamente de Política. Leamos, en el orden y traducción del propio Marcovich ${ }^{24}$, dichos fragmentos:

B43: Un desafuero desenfrenado debe ser sofocado con mayor razón que un incendio público ${ }^{25}$.

B44: El pueblo debe luchar por su constitución (ley) lo mismo que por sus murallas ${ }^{26}$.

B33: También esto es una ley: obedecer la voluntad de un solo hombre ${ }^{27}$.

B121: Los Efesios harían lo mejor ahorcándose todos, cada hombre adulto sin excepción, y dejando la ciudad a los impúberes menores, ya que han expulsado a Hermodoro, el más útil (o capaz) hombre entre ellos, alegando: 'Entre nosotros que nadie sea el MAS útil; de lo contrario, que sea en otra parte y entre otros ${ }^{28}$. B125a: ¡Que jamás falte la riqueza a los Efesios, para que quede comprobada su bellaquería (perversidad)! ${ }^{29}$.

Estos fragmentos muestran, con bastante claridad, la tendencia política de Heráclito. B43 censura la $\ddot{\beta} ß \iota \iota \varsigma$ con la que la clase opulenta de Éfeso conducía sus vidas, como lo hemos revisado antes a propósito del análisis de Caballero. B44 propone una lucha $(\mu \alpha ́ \chi \varepsilon \sigma \theta \alpha \iota)$ necesaria $(\chi \varrho \eta ́)$ por las murallas de la ciudad lo mismo que por la ley o norma de vida $(v o ́ \mu o \varsigma)$, donde se ve la clara relación, que queremos resaltar entre ley y naturaleza, o entre ley y orden social, como era típico, según vimos con Jaeger, en las concepciones jurídicas de la Grecia arcaica. B33

${ }^{22}$ En este último grupo pueden encontrarse fragmentos como el 22 B 115 DK, que dice que "es

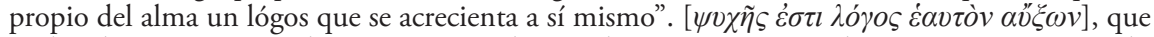
en la edición canónica de Hermann Diels y Walter Kranz se considera genuino. Marcovich, p. 569, traduce aquí $\lambda o ́$ joৎ por razón numérica "(numerical) ratio". Las razones que aduce Marcovich para considerar espurio el fragmento B 115 son: "a) porque es transmitido bajo el nombre de Sócrates [por Estobeo]; b) debido a la similaridad entre este fragmento y otros casos como [aquí cita textos de Plutarco, Aristóteles, y Aecio] y c) La medida parece implicar algo constante en la Física de Heráclito [y cita 22 B 31 DK]: una "medida que se aumenta a sí misma" no es probable para Heráclito", p. 569.

${ }^{23}$ Utilizaremos la numeración establecida por Diels para los fragmentos que citemos.

${ }^{24}$ M. Marcovich 1968: 123-126.

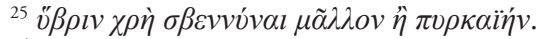

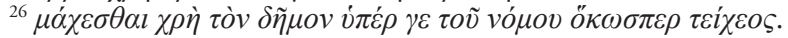

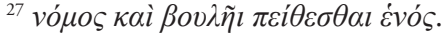

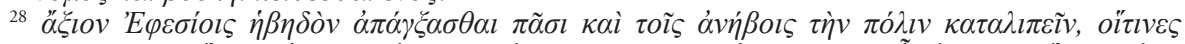

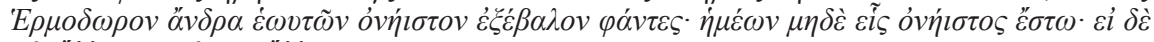
$\mu \eta \dot{\eta}, \ddot{\alpha} \lambda \lambda \eta \imath \tau \varepsilon \kappa \alpha i ̀ \mu \varepsilon \tau^{\prime} \ddot{\alpha} \lambda \lambda \omega v$.

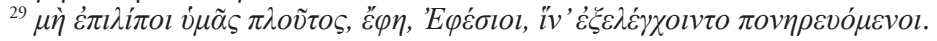


es complejo, dado que puede entenderse que lo que quiere decir Heráclito es que debe obedecerse la voluntad de un solo hombre (غ́vós) o bien podría pensarse que se requiere obedecer la voluntad de 'lo uno', es decir, $\tau \grave{o} \varepsilon \ddot{v}$, porque la forma غ̇vós, es igual en masculino y en neutro. B121 apoya al aludido Hermodoro y sus reformas, consideradas por el filósofo seguramente "más útiles". Y B125a censura también, de manera sarcástica, la riqueza ostensiva de los efesios.

Ahora bien, es natural que estas opiniones dadas casi "al boleo" por Heráclito, con el sarcasmo típico de su críptico estilo, se fundan ya no en opiniones, sino en creencias profundas de Heráclito, creencias que nos demuestran con toda su potencia el modus vivendi que aprecia el filósofo de Éfeso. Esto significa, además, que estos fragmentos o palabras de Heráclito no fueron dichas ni escritas al azar, sino que se enmarcaron dentro del desarrollo histórico-político de la ciudad de Éfeso y sólo de ahí surgieron como la respuesta del filósofo a su propia contemporaneidad. Es por ello que no es posible pensar un entendimiento del filósofo efesio sin referencias a sus condiciones de vida, a las condiciones en las que se fue fraguando y donde terminó de desarrollarse su pensamiento. Un

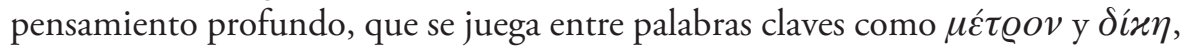

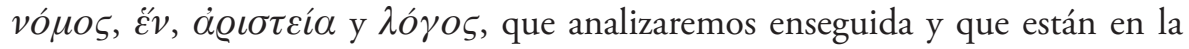
base de las opinioes o reflexiones que Heráclito emite en sus sentencias.

\section{II.1. Fragmento B43 y la idea de medida y justicia}

La idea que subyace al fragmento B43 es la idea de mesura, justeza y por qué no, Justicia, con mayúscula. Esta idea la encontramos en ciertos fragmentos. El primero que traeremos a colación es el B30, especialmente su última parte:

B30: Este kósmos $^{30}$, el mismo de todas las cosas, no lo hizo ni alguno de los dioses ni de los hombres, sino que siempre era, es y será un fuego siempreviviente, encendiéndose con medidas y extinguiéndose con medidas ${ }^{31}$

Si pensamos en este fragmento, es fácil advertir que se trata de un fragmento principalmente cosmológico -como es tratado por Kirk, por ejemplo- y es analizado por los estudiosos dentro del tema "orden del cosmos" o de la

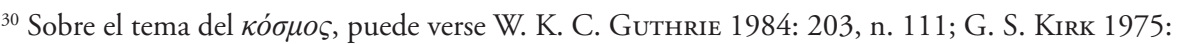
312 ss; M. Conche 1986: 279-280.

${ }^{31}$ Las traducciones de los fragmentos que no son los del Grupo 23 de Marcovich son propias.

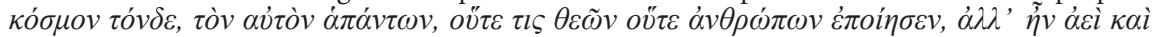

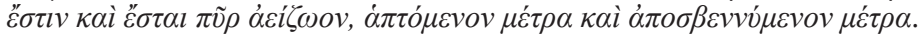


Física de Heráclito -como hace Marcovich- pero en su parte final nos da una luz sobre la idea de mesura, aplicada nada menos que al fuego eterno, íntimo constituyente del universo. El movimiento del principio primordial, del que son transformación todas las cosas, como puede verse en el fragmento B90 ${ }^{32}$ ("Del fuego son alternación todas las cosas y el fuego de todas las cosas, de la misma manera que son alternación del oro las riquezas y el oro de las riquezas"), está reglado por su estructura interna, es decir, no puede rebasar sus propios límites, que están ordenados, si se quiere, por una suerte de Justicia cósmica, como la aplicada al sol que rebasa sus medidas en el fragmento B94, y que sabrá, porque ése es su ser, devolverlo a su sitio ("Helios no quebrantará los límites, y si no, las Erinias, servidoras de Dike, le descubrirán) ${ }^{33}$.

Este motivo reaparece en otros fragmentos y es intrínseco a la idea de

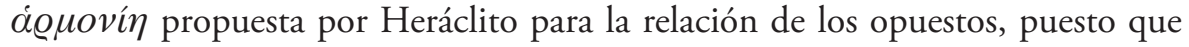
la armonía es un algo que surge del choque de los contrarios, como en la tensión del arco y la lira, y se muestra en una bidimensionalidad que la presenta por una lado como visible ( $\phi \alpha \nu \varepsilon \varrho \eta ́)$, es decir, en el ámbito del fenómeno si se quiere y, por otro lado, la presenta como invisible ( $\dot{\alpha} \phi \alpha \nu \eta ́ s)$, esto es, como aquella "ligazón" que une los contrarios, aquella fuerza según la cual los contrarios están unidos de alguna manera. Es fácil ver en la armonía invisible la mano del lógos en tanto principio ordenador, uniente de todas las cosas. No es posible aquí ahondar detalladamente en este asunto.

\section{2. Fragmento B44 y el vó $\mu o \varsigma$}

Sobre el tema que presenta el fragmento B44, la idea de la ley que hay que resguardar de la misma manera que las murallas de la ciudad, es muy posible que se esté haciendo alusión al vó $\operatorname{co\varsigma } \theta \varepsilon i ̂ o v$ del fragmento B114, en el que leemos:

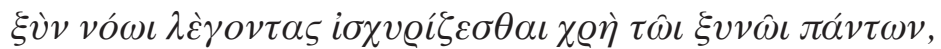

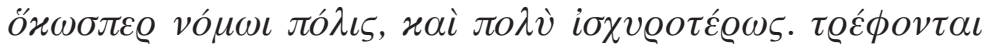

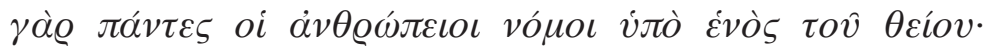

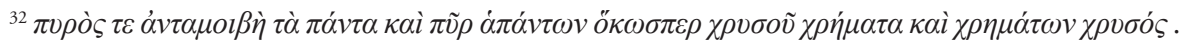

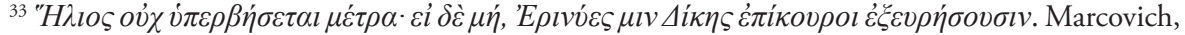
p. 276, comenta: "Thus the saying seems to illustrate the necessity of measures for the cosmic balance; (...). The future tense ovं $\dot{v} \pi \varepsilon \rho \beta \dot{\eta} \sigma \varepsilon \tau \alpha l$ possibly implies the improbability of such a happening ('Sun will never transgress his bounds')" Marcovich , para el caso de las Erinias cita un pasaje de la Teología de Jaeger, donde dice: "Las Erinias vengan toda violación de lo que llamaríamos las leyes naturales de la vida”, p. 233, n. 31 de W. JAEGER 2003, quien refiere a su vez a un motivo Homérico, Il., XIX, 418.
} 
Sebastián Aguilera Q. : La política del logos: reflexiones sobre el pensamiento político...

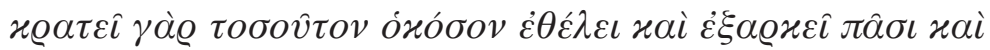
$\pi \varepsilon \varrho \iota \iota^{\prime} v \varepsilon \tau \alpha \iota$ [Es necesario que los que hablan con inteligencia se fortalezcan con lo común de todas las cosas, de la misma forma que la pólis con la ley, y de manera mucho más fuerte. Pues, todas las leyes humanas son alimentadas por una única (ley) divina; en efecto, ella reina tanto cuanto quiere, y no sólo basta para todas las cosas, sino que también las sobrepasa]

Este fragmento muestra que la ley que articula el todo es una ley divina. Fuente de cualquier ley humana. Esta ley divina está en todas las cosas, alcanza a todas pero no es sólo eso, sino que las sobrepasa a todas, en el sentido en que lo divino sobrepasa a lo humano, como entiende Kirk ${ }^{34}$. Esta ley además, nos dice Heráclito, es $\ddot{\varepsilon} v$, i. e., una sola, única. Claramente se refiere al lógos que gobierna el devenir y según el cual suceden todas las cosas. Kirk-Raven se dan cuenta de esto también: "Dios no puede distinguirse, en este caso [fr. 67], esencialmente del Logos, y el Logos es, entre otras cosas, el constitutivo de las cosas que las hace opuestas y el que garantiza que el cambio entre los opuestos ha de ser proporcional y equilibrado por todas partes" 35 . Entendemos entonces el vó $\mu o \varsigma$ por el que se impele a luchar no como una ley sectorial ${ }^{36}$, establecida en tal o cual pólis de Grecia, sino referida a la ley divina, de la cual se nutre toda ley humana. Es esta noción de ley, entendida como el lógos que articula y regula todo lo que es, la que está detrás del fragmento $\mathrm{B} 44^{37}$, es por ello que se puede hablar, en cierto sentido, de iusnaturalismo en Heráclito o de derecho natural, como entiende Jaeger, aunque habría que pensar también en la conexión que existe entre esta idea de ley natural y el obrar del hombre. Esta ley, como vimos, es la

${ }^{34}$ Cf. G. S. KirK 1975: 48-56, esp. 55.

35 G. S. Kirk, J. E. Raven Y M. Schofield 19872: 279. G. S. Kirk 1975: 200, dice: god is the opposites. Ver también Guthrie, W. K. C., 1984: 435: "El fuego se acoplaba particularmente bien para encarnar esta ley [la ley de la jungla, puesto que todo se origina "mediante la lucha» y la Guerra es el seńor de todo]. Una llama puede aparecer firme e inalterable como en una vela, pero se está renovando constantemente a sí misma por la destrucción de la masa combustible y produciendo calor y, a veces, humo. La afirmación referente al río expresa la misma verdad de una estabilidad aparente o formal, unida a un cambio continuo del elemento material". Cf. sin embargo, M. Marcovich 20012: 95: "The Logos is only analogous to the single divine Law, but not identical with it".

${ }^{36}$ Cf. J. Bollack \& H. Wismann 1972: 162, citado en R. Caballero 2012 b.

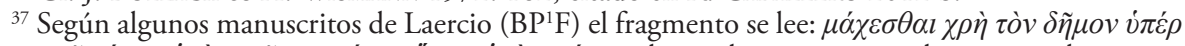

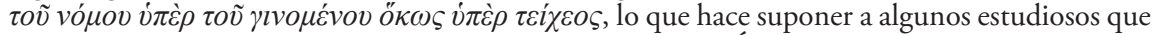
de la ley de que se habla en este fragmento ha de ser la ley de Éfeso y no una ley Universal, como se vio entienden Kirk-Raven y otros. 
ley que pone todo en abierta oposición pero que con ello armoniza todo. En este sentido, la ley que nutre a todas las demás, como ven Kirk-Raven, es aquella "que garantiza el cambio entre los opuestos" y por tanto, la ley por la que debe luchar el pueblo, en B44, no es otra que esa. Más allá de aquello no podemos conjeturar, aunque quizá la tesis de Caballero se acerque en cierta medida y concretice un poco más el fragmento, que aún parece demasiado abstracto.

Caballero entiende $\mathrm{e}^{38}$ nómos como costumbre o norma de vida y lo relaciona con la ley divina de B114, en la que se apoyaría el nómos de B44, y entiende entonces que esta ley divina es la ley de la coincidencia de los contrarios, de tal modo que lo que Heráclito está diciendo es que no debe dejar el pueblo efesio que exista algún otro que sea dominante y que con su dominación desequilibre la balanza establecida por la ley divina, la ley de la armonía de los contrarios:

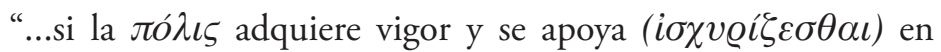
sus propios usos y normas tradicionales (ö es porque esas normas y hábitos de conducta, como todas las normas humanas, se alimentan de "una única (norma) divina"

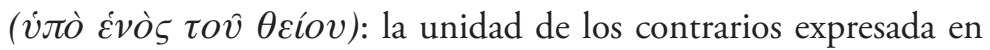
el Discurso ( $\lambda o ́ \gamma o \varsigma$, cf. B 1). Es precisamente esa unidad entre intereses divergentes el bien último que es preciso proteger en la ciudad, como si fuese la muralla que salva a los ciudadanos de la destrucción. Para Heráclito, la fuerza del vómo se resquebraja y

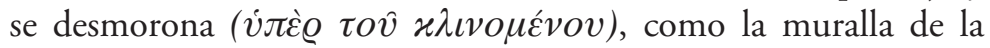
ciudad (ö $\varkappa \omega \sigma \varepsilon \varepsilon \tau \varepsilon \dot{\chi} \chi \varepsilon \sigma \varsigma$ ), si se concede excesivo poder a uno de los polos de la comunidad, ya sea la nobleza, el tirano de turno o el pueblo. Los fragmentos de Heráclito denunciando la $\ddot{v} \beta \varrho \iota \varsigma$ (B

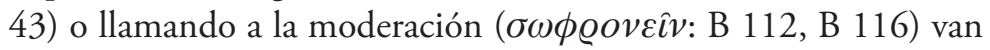
en esa misma línea"39.

Es interesante esta interpretación en la medida en que avanza del texto heraclíteo a los acontecimientos históricos que quizá hicieron surgir aquel texto. Pero, si de seguridad se trata, es sabido que al respecto casi todo es pura conjetura,

\footnotetext{
${ }^{38} \mathrm{R}$. Caballero $2012 \mathrm{~b}$, propone la siguiente lectura y traducción del texto: $\mu \alpha \dot{\alpha} \chi \varepsilon \sigma \theta \alpha l \chi \rho \grave{\eta} \tau \grave{v} v$

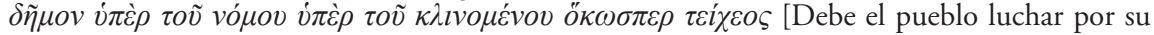
norma de vida, por la que se está derrumbando, como si fuera su propia muralla] Cf. también R. Caballero 2008.

${ }^{39}$ R. Caballero 2012 b.
} 
ya que no hay datos fidedignos para relacionar de manera directa el texto y tal o cual acontecimiento histórico. Si bien la argumentación de Caballero va en el sentido de relacionar la ley divina con la ley o norma de vida del pueblo, no queda claro si pensamos que aquella norma de vida, aquella ley divina, el Lógos, también se reviste de caracteres que le impugnan una cierta necesidad en su acaecer, esto es, nosotros creemos que en Heráclito, la ley del cambio, de los contrarios, no depende bajo ningún sentido o no es posible aplicarla con total ligereza al devenir de una comunidad política, por ejemplo. Si bien podemos entender separadamente el nómos de B 44 como una manifestación imperfecta, si se quiere ${ }^{40}$, del nómos divino de B 114, no quiere decir esto más que las leyes humanas, en tanto que humanas, es decir, faltas de comprensión, no son idénticas a las leyes divinas o a la única ley divina. No es posible decir sin más que el pueblo ha de luchar por la ley divina, sino sólo por su ley, ley que en el pensamiento de Heráclito se nutre y depende, o mejor, debería depender, de aquella única ley divina. No podemos suponer, como hace Caballero, que se trate, sin más, de la misma ley, del mismo nómos, aunque sí estén relacionados. Puesto que no podemos pensar que la norma de vida por la que hay que luchar, donde luchar significa algún grado de deterioro o pérdida de esa norma de vida, sea la "lucha de los contrarios" en tanto que norma de "funcionamiento del kósmos", puesto que sería luchar por algo por lo que no es dable luchar, ya que acontece necesariamente.

Para terminar con el fr. B44 podemos decir que es claro reflejo de lo que está pensando Heráclito cuando nos habla de $v o ́ \mu o \varsigma$, y Jaeger lo aclara magistralmente:

"Pero Heráclito no encuentra lo Divino en lo eterno, lo imperecedero y lo omnipotente tan sólo; por el contrario, conecta esta idea exactamente con aquel mismo principio legal que Anaximandro creía haber encontrado en el proceso de la naturaleza. Este principio resulta generalizado hasta muy por encima del más alto concepto de legalidad y moralidad humana, la idea de ley: ahora se lo entiende como la ley de todas las demás leyes. (...) Y el filósofo toca ahora su diana, llamando a los hombres a despertar

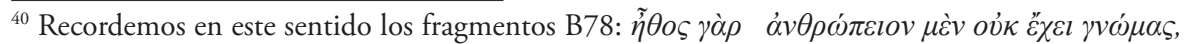

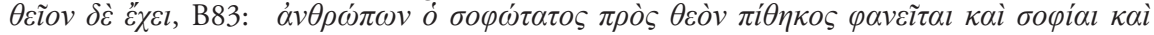

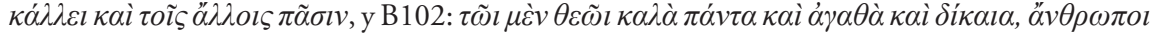

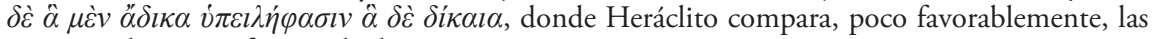
potencias humanas frente a la divina.
} 
y obrar como manda esta ley divina. Este aspecto teológico hace ver con suma claridad qué tan profundamente difiere la ley de Heráclito de lo que nosotros mentamos cuando hablamos de una "ley de la naturaleza". Una "ley de la naturaleza" es simplemente una fórumla general para describir un complejo específico de hechos observados, mientras que la ley divina de Heráclito es algo auténticamente normativo. Es la más alta norma del proceso cósmico y la cosa que da a este proceso su significación y valor" ${ }^{31}$.

Cuando Heráclito habla de ley no se refiere solamente a la ley mundana, sino a la ley divina, que no es otra cosa que el lógos, según el cual todo acontece (B1) ${ }^{42}$. Dios, lo divino, no es para Heráclito algo supraterrenal, aunque sí eterno, sino que es inmanente, es un principio fundamental inmanente, puesto que Dios es los opuestos y los opuestos y su lucha son el devenir del mundo, Dios es el devenir; pero no se trata de algo banal, muy por el contrario, responde a la intuición fundamental de unidad entre lo divino, el mundo natural y lo humano, propia de Heráclito, pero también propia del entorno filosófico jónico ${ }^{43}$. Esta idea de unidad es fundamental para explicar el accionar político del hombre en la sociedad. Es por ello que Heráclito en B44 dice: hay que luchar por la ley de la pólis del mismo modo que por las murallas, es decir, igual de importante es la ley que rige la pólis, que en Heráclito, en última instancia, no es otra que la ley divina

${ }^{41}$ W. JAEGER 2003: 118.

${ }^{42}$ Cf. El lúcido comentario de W. JAEGer 2003: 117: "El logos no es sólo lo universal, sino también lo común. Pero si bien esto hace de él algo afín a la ley del estado que liga a todos los ciudadanos, es aún mucho más que la ley incluso de la república más grande y más poderosa, pues el logos es

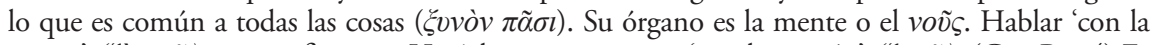

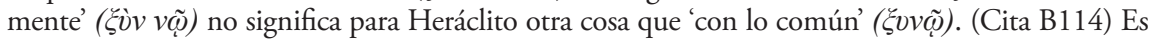
la primera vez que la idea de 'ley' aparece en el pensamiento filosófico; lo que es más, ahora se la considera como el objeto más alto y más universal conocimiento; el término no se usa en su simple sentido político, sino que se ha extendido hasta cubrir la naturaleza propia de la realidad misma”.

${ }^{43}$ No por nada la segunda filosofía jónica, que comienza con Diógenes de Apolonia, lo que pretende es, en gran medida, explicar aquella intuición tendiente a la inmanencia que, en palabras de Angel Cappelletti, puede llamarse autoconsciencia del panteísmo jónico. Cf. A. CAPpelletti 1974: 19-20. Cappelletti dice: "A él [a Diógenes apoloniata], le toca, en efecto, fundamentar el monismo que, en sus remotos orígenes prefilosóficos, estaba vinculado a una intuición metafísico-mística. A él le corresponde también identificar o, por mejor decir, tomar conciencia de la identidad de materia, vida y espíritu (o inteligencia) que está implícita en la noción de $\varphi v ́ \sigma \iota \varsigma$, usada y manejada por los milesios y por Heráclito. A él le compete, en fin, darse cuenta plenamente de la identidad básica de la Naturaleza ( $\varphi v ́ \sigma \iota \varsigma$ y Dios $(\theta \varepsilon o ́ \varsigma)$ o, en términos que pueden sonar anacrónicos pero que corresponden dentro de ciertos límites a una situación ideológica, asumir la autoconciencia del panteísmo jónico”. 
o el lógos, que las murallas que la protegen del enemigo. Pero el énfasis, Heráclito lo coloca en la ley, es decir, se está diciendo, en último término, que lo importante no son sólo las murallas de la ciudad, sino que más importante aún es la ley ${ }^{44}$, luchar por la ley o norma de vida, la norma divina, el contenido esencial del lógos en Heráclito.

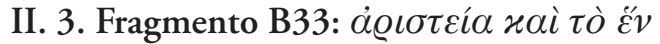

En B33 Heráclito expresa de manera poco clara la obediencia que el hombre debería tener, obediencia que se presenta como el respeto por la costumbre, ley o norma de obedecer la voluntad de uno. El fragmento presenta problemas en su traducción y por lo tanto en su interpretación. Analicemos las opciones con el fin de llegar a algo medianamente claro al respecto. Podemos entender la $\beta o v \lambda \eta$ Évós de dos manera: a) como la voluntad de un solo hombre, lo que es verosímil, quizá historiográficamente, con los testimonios que aluden a la reforma política de Hermodoro ${ }^{45}$, y a su vez con las ideas aristocráticas del filósofo de Éfeso, como

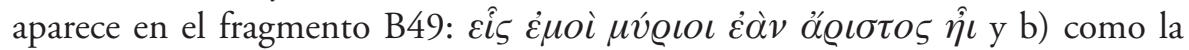
voluntad de lo uno, identificando este uno al mismo hén que aparece, por ejemplo,

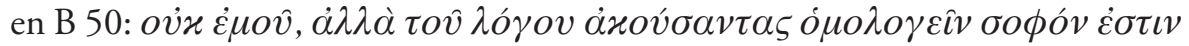

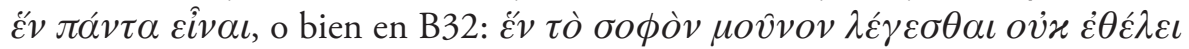

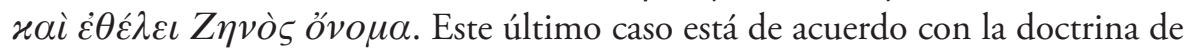
la unidad de los contrarios de Heráclito o, si se quiere, de que el ser es uno.

No dejemos, en principio, ninguna de las dos posibilidades de lado. Tengamos en cuenta que ambas son factibles, puesto que غ́vós puede significar tanto de uno como de lo uno, puesto que la forma genitiva masculina y neutra del pronombre $\varepsilon \hat{i} \zeta$ - $\mu i \alpha$ - $\check{\varepsilon} v$ es la misma. Si se refiere a un hombre ( $\varepsilon \hat{i} \zeta)$, que sería probabilísimamente Hermodoro, éste tendría que ser el mejor hombre, puesto que así valdría que fuese a quien el pueblo debe obedecer. Ser el mejor en Heráclito es ser sabio, y la única forma de conseguir la sabiduría es despertar al mundo del lógos, de la armonía invisible, comprender el fundamento que hace que este mundo devenga como el fuego en B30, mesuradamente por medio de la guerra y lucha de

\footnotetext{
${ }^{44}$ Prueba de ello es también el comentario de M. Marcovich 20012: 534: “Heraclitus' insistence on respect for Law might be due to a deeper, philosophical reason, in vew of fr. 23 (DK 112+2): Law is one of the manifestations of a higher and sacred principle, i. e. "What-is-common-to-

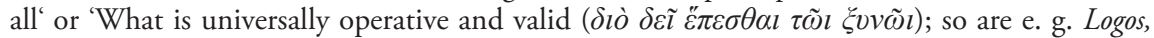
Polemos; the everliving Fire." vó $\mu$ s, en todo caso se refiere no a la ley como la concebimos nosotros, sino a un uso, costumbre o norma de vida; ver P. Chantraine 1968: s. v. vé́ $\mu \omega$. ${ }^{45}$ Cf. las Epistolas Pseudo-heracliteas, A. Cappelletti 1960; R. Caballero 2012 a.
} 


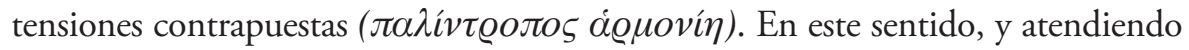
el significado de B50, entendiendo que el $\dot{\mu} \% о \lambda o \gamma \varepsilon \hat{\imath} \nu$ significa una suerte de ser uno con aquella verdad que es el lógos, podríamos decir que aquel $\varepsilon \hat{i}$ s debería, si es el mejor, y suponemos que Heráclito se refiere con mucha seguridad a un hombre óptimo en B33, estar de alguna manera siendo o viviendo en la verdad del lógos, expresada claramente en B50, de tal modo que ambas lecturas de B33 nos llevan a lo mismo. La voluntad de lo uno no es otra cosa que el contenido del lógos. Y a su vez, la voluntad de uno solo, no es otra cosa, asimismo, que el contenido del lógos.

De modo que la aristeía está estrechamente ligada al significado de tò hén en Heráclito. Aquel que quiera gobernar deberá ser el mejor, sólo ahí tiene la valía de mil hombres, pero ello sólo es posible si se ha escuchado o prestado atención a lo que el lógos muestra ${ }^{46}$ y se ha concordado, es decir, se ha prácticamente hecho uno con aquella verdad, cosa que significa no otra cosa que vivir conforme al lógos, seguirle los pasos, como se expresa J. E. Rivera.

Para los efectos de una interpretación política, ésta se vería fortalecida si pensamos que lo que está detrás en esta ambigüedad de lectura en B33 es lo $\check{\varepsilon} v$, porque ese $\ddot{\varepsilon} v$ es el contenido capital del lógos de Heráclito, el lógos uniente que unifica la naturaleza, Dios y el hombre en una visión de conjunto que es la base de la enseñanaza de Heráclito. No sin razón Jaeger vió también estas conexiones, y pudo comprender que el nómos divino, al cual se referiría el fragmento B33, además de constituir lo que él llama "religión cósmica" en Heráclito, funda la norma de vida del hombre en la norma del mundo ${ }^{47}$, como dio a entender Heráclito en B114, que revisamos anteriormente. Podríamos incluso hablar de una "política cósmica" o, descontextualizando quizá una feliz expresión de Antonio Capizzi, hablar de una "República Cósmica” en Heráclito, en el sentido de un orden social en el que esté incorporado el propio devenir real y verdadero del cosmos.

\section{4. Fragmento B 121 y la legislación del $\lambda o ́ \gamma o \varsigma$}

Pensar que el $\dot{\varepsilon} v o ́ \varsigma$ se está refiriendo a $\varepsilon \hat{i} \zeta$, por ejemplo, del fragmento B49, no es contrario a pensarlo como referido a la unidad total, al $\tilde{\varepsilon} v$ de B50, sino que, más bien, el hecho refuerza que el hombre sabio, el que vale mil para Heráclito, es aquel despierto que ha comprendido la verdad fundamental de la unidad de las cosas. Por ello, quien así comprende, merece de Heráclito la aporbación, como

${ }^{46}$ Cf. M. Heidegger 1994; M. Heidegger \& E. Fink 1986; J. E. Rivera 2006.

${ }^{47}$ Cf. W. Jaeger 2006: 180. R. Caballero 2012 b, realiza un excelente análisis de los testimonios para explicar B 44 y el tema de la ley. 
claramente puede estar implícito en el fragmento B 121, donde Heráclito da el favor a Hermodoro por sobre sus demás compatriotas, porque es el más valioso entre ellos, es decir, el mejor. Así, el gobernante bueno, el mejor gobernante, tiene que vivir en atención al lógos, es decir, vivir conforme a lo que el lógos significa en Heráclito en tanto una doctrina cuyos contenidos principales son la armonía de los contrarios, el incesante cambio y la unidad de la totalidad.

Pero, para ir un poco más allá, si nos preguntamos por el fundamento de esta alta estima que Heráclito tiene por aquello "mejor", sea hombre, situación, principio, etc., podemos encontrarlo en la famosa oposición entre hombres dormidos - hombres despiertos ante el lógos, que aparece al inicio de su libro ${ }^{48}$, es decir, en el fragmento B1:

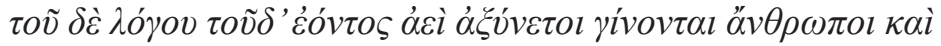

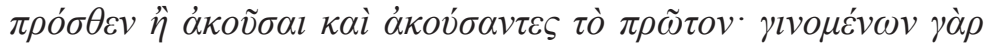

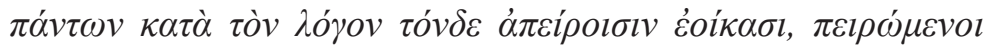

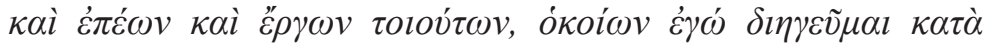

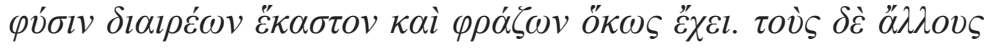

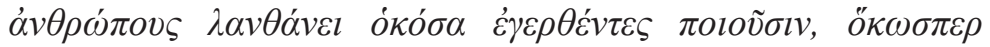

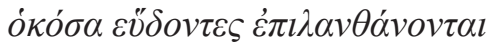

[Estando este lógos presente, siempre los hombres hállanse incapaces de comprenderlo, tanto antes de escucharlo como habiéndolo escuchado por vez primera. Siendo, pues, todas las cosas según este lógos, ellos se asemejan a inexpertos, experimentando tanto palabras proféticas como actos de esta naturaleza, como los describo yo, distinguiendo, según la naturaleza de cada cosa y dando a entender cómo es. Sin embargo, se ocultan a los demás hombres cuantas cosas hacen estando despiertos, de la misma manera como dan al olvido cuanto hacen estando dormidos]

Hay que aclarar nuestra opción, como la de muchos intérpretes, de no traducir la palabra griega $\lambda o ́ \gamma o \varsigma$. En principio creemos que en B1 Heráclito, al hablar acerca del lógos no está meramente hablando de su propia filosofía, sino que está dotando

${ }^{48}$ Si no al inicio, al menos iniciando su discurso fuerte sobre la doctrina del lógos. Cf. por ejemplo, M. Marcovich 20012 pone el fragmento 22 B 1 DK en el primer lugar de su edición de Heráclito; A. Capızzi 1979 también lo pone como el primero; G. S. KirK 1975 y Kirk-Raven 1987 también lo pone al inicio de la exposición de su pensamiento; CH. KaHN 1979 también; Cf. quienes no lo ubican en el primer lugar, por ejemplo, I. Brwater 1877; J. Mansfeld 2008; M. Conche 1986; G. Colli 2010 y la refectio de S. N. Mouraviev 2011 (Citado por R. Caballero 2012), y cf. también su propio comentario a su obra en S. N. Mouraviev 2013: 195-218. 
de nuevo sentido al vocablo para expresar lo que está pensando acerca de la constitución y fundamento del mundo que lo rodea. Esto es así por las numerosas coinicdencias de lógos con dios, fuego, pólemos padre de todas las cosas, la armonía oculta, etcétera; todas aquellas ideas que expresan, como diríamos, en la línea del problema del ser, el ser mismo. Para simplificarlo, el lógos sería en Heráclito el ser. Ciertamente, no es aquí la ocasión para sumergirnos en tan complejo problema, sino que esbozamos un planteamiento general que está detrás de nuestra interpretación de la política del efesio, como ya hemos hecho mención.

Entonces, en el fragmento B1, Heráclito está hablando del ser, frente al cual los hombres se quedan atónitos y se muestran faltos de inteligencia, aun teniendo experiencia cotidiana con él. Se trata de captar aquello que está oculto, detrás de las apariencias, la armonía oculta, siempre más poderosa que la visible, que la manifiesta. Sin embargo, esta armonía oculta, esto que se encuentra en un aparente "detrás" es lo que posibilita todo lo real, e incluso podríamos decir que se trata de lo divino, de dios. Pero debemos dejar a un lado nuestra preconcepción -que viene del mundo cristiano- de un dios personal, separado de todo, aunque el mismo Heráclito califique a lo sabio como separado de todas las cosas ( $\pi \alpha ́ v \tau \omega \nu \varkappa \varepsilon \chi \omega \varrho \iota \sigma \mu \varepsilon ́ v o v)$ en el fragmento B108. Lo cierto aquí es que esto divino lo gobierna todo, puede cuanto quiere y está ahí, está presente, frente a los hombres, y además, tiene características de ser algo único, vale decir, este ser, que posibilita, o expresa ${ }^{49}$ todo lo real es uno solo. Aunque debemos tener cuidado al decir que es uno, puesto que de esta manera no podríamos comprender lo que el mismo Heráclito dice en repetidas ocasiones, que todo es uno, de lo uno todo y todo de lo uno, etcétera. No se trata de que el ser sea uno, sino que es uno, pero ese uno es, a la vez, todo, no por nada se ha hablado de un "monismo panteísta" ${ }^{50}$ o de una "autoconciencia de panteísmo" "51, puesto que este lógos tiene tanto los caracteres de algo uno como

${ }^{49}$ Cf. la decisión de G. Colli 2010, por traducir el lógos de Heráclito por "espressione”. Cf. También, G. Colli 1988: 203, n. 20: "Il significato di logos è perfettamente unitario, si riassume in: legge del fenomeno, cioè rappresentazione, rapporto di soggetto e oggeto, in cui il soggetto è anche oggetto e viceversa (si ricordi che i contrari non sono altro se non individualità interiori). Il logos sarà quindi anche espressione in genere, in quanto manifestazione, apparenza del noumeno, così in particolare parola e pensiero umano. La filosofia di Eraclito, pero il fatto che esprime la verità assoluta, può dirsi senźaltro il logos. Naturalmente l'uso concreto del termine nei frammenti varierà dall'indicazione della rappresentazione in quanto tale, come legge, a quella di una singola rappresentazione".

50 W. Capelle 1981. 
los caracteres de todo, puesto que es, como dice el fragmento B67 hablando de dios: todos los opuestos ( $\tau \alpha \dot{v} \alpha \nu \tau i \alpha \alpha \check{\alpha} \pi \alpha \nu \tau \alpha)$.

Es ésta la clave del asunto: el lógos, respecto del cual los hombres son o no capaces de comprender. La opinión de Heráclito es que los hombres siempre se muestran incapaces de comprender el lógos, pero no se trata de una incomprensión menor, como no comprender el teorema de Pitágoras o la trigonometría, se trata de algo más profundo que toca al hombre en su fibra más íntima: su razón, aquello en virtud de lo cual se diferencia de muchas especies y que es una de sus notas esenciales e incluso LA nota por antonomasia, si entendemos por razón la capacidad del lenguaje y entendemos que lo propio del hombre es, como ya lo notó Aristóteles ${ }^{52}$, el lenguaje, la palabra. Esta incomprensión es manifestada por Heráclito como propia de los idiotas, aquellos que no tienen más inteligencia que el propio ganado, con el que compara a la muchedumbre. Estos hombres parecen dormidos incluso cuando están despiertos, puesto que no comprenden el fundamento que actúa delante de ellos y que incluso los hace ser, pues el lógos es lo más íntimo no solo en la constitución del mundo, sino también es lo más profundo en el alma del hombre, como da a entender el framgmento B115: $\psi v \chi \hat{\eta} \varsigma \dot{\varepsilon} \sigma \tau \iota \lambda \hat{o} \gamma o \varsigma \dot{\varepsilon} \alpha v \tau o ̀ v \alpha \grave{v} \xi \omega v$ y como dice explícitamente el fragmento

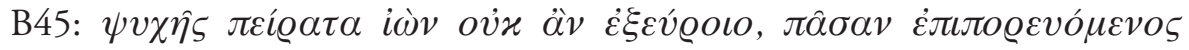

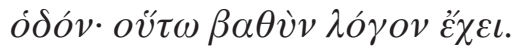

Este lógos, no solamente es ordenador de todo, ley del universo según la cual todo acontece, sino que además, por esto mismo, es común a todos los hombres, como ha dicho en B2 (Texto de G. Colli): $\delta \iota \grave{o} \delta \varepsilon \hat{\imath} \varepsilon \ddot{\tau} \tau \varepsilon \sigma \theta \alpha \iota \tau \hat{\omega} \iota$

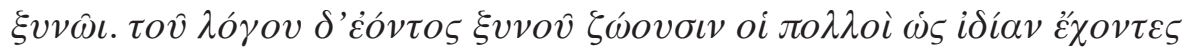

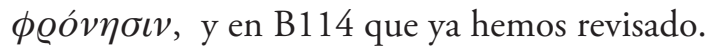

Y siendo el lógos común a todos los hombres, tanto porque lo tienen enfrente de sí como en tanto lo llevan dentro de sí, pues es el fondo del alma, es fácil afirmar que se trata, en el fondo, de lo mismo, aquello que está en nosotros mismos, el lógos del alma, está en el alma de los demás, hombres, puesto que todos tienen la capacidad de comprender y tener inteligencia, como aclara Heráclito en B116:

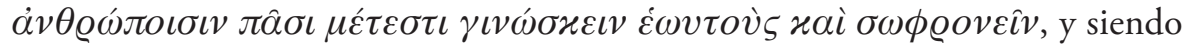
esto así y entendiendo que lo que el lógos nos dice si le prestamos oído (B50) es

${ }^{51}$ A. Cappelletti 1974.

${ }^{52}$ Ar. Pol. 1253 a 10 ss; E. N. 1170 b 11 ss. 
que todo es uno, es fácil suponer que el principio regente del cosmos es, a la vez, nuestro propio principio gobernante, si lo sabemos oir y seguir. Por ello, este lógos bien puede ser el que Heráclito encontró en el ejercicio de autoexamen que muestra el fragmento B101: $\dot{\varepsilon} \delta \iota \zeta \eta \sigma \alpha ́ \mu \eta v \varepsilon \dot{\varepsilon} \mu \varepsilon \omega v \tau o ́ v$. Este lógos está presente ante nuestros ojos y es lo que une nuestra vida a la vida del mundo. Como esto

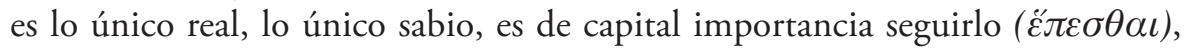
puesto que de lo contrario entraríamos en los desafueros de la opulencia, en la ű $\varrho ı \varsigma$ que Heráclito critica y que se aleja de la sabiduría y de estar acorde al devenir del mundo.

\section{Consideraciones finales}

¿Qué puede hacer el hombre con eso? Esta idea fundamenta el pilar de la igualdad entre los hombres, pues a todos es común la inteligencia (B113: छvvóv

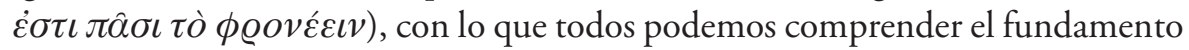
de dicha igualdad. El ámbito en donde se da o no esta comprensión divide a los hombres en los dos grupos de que hablamos a propósito del fragmento B1, es decir, por una parte de los dormidos, que son quienes no comprenden lo que está frente a sus ojos, y estando presentes, como dice Heráclito en B34, están ausentes

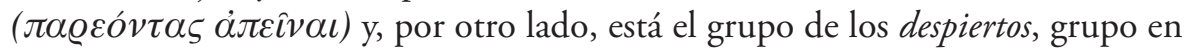
el que sin duda se sentía perteneciente el mismo Heráclito; aquéllos que han captado la esencia del mundo, la norma divina que hace suceder todo en un ciclo sin fin y que incluye tanto el devenir material del propio mundo y del hombre como el devenir espiritual, o interior si se quiere, del propio hombre, aquel que ha comprendido y a la vez comienza a vivir según eso que ha comprendido. Si confiamos sólo en Heráclito, cosa que es a todas luces ficticia, sólo él y Hermodoro y quizá el orador Bías, han comprendido el sentido del lógos que todo lo muestra, sólamente porque estos nombres están entre los elogiados por Heráclito, no como los de Homero, Hesiodo, Hecateo, Pitágoras, etcétera. Pero, esta distinción no es totalmente lapidaria y desesperanzadora para el hombre, puesto que aquel dormido, sólo por ser hombre, tiene, según Heráclito, la capacidad de conocerce a sí mismo, y con ello, puede, si presta la debida atención, despertar a lo común, comprender el lógos.

Aquí radica uno de los puntos esenciales dentro del pensamiento político de Heráclito, pues esta aparente división entre capaces e incapaces de comprender no es más que una constatación de hecho de parte de Heráclito, pues como veíamos, él mismo abre la posibilidad de que el hombre que se encuentra 
dormido, pueda despertar y comprender aquella ley divina que nutre o inspira todas las leyes humanas que él cree conocer. Por ello, podríamos cuestionar el llamado "desprecio" que siente Heráclito hacia el ser humano, pues éste no sería más que un desprecio de aquello que en el hombre es, según él, inferior, como lo sería no ser atentos al lógos que gobierna todo en y a través de todo.

Al comprender esta esencia, el lógos, la inteligencia del hombre, su sabiduría,

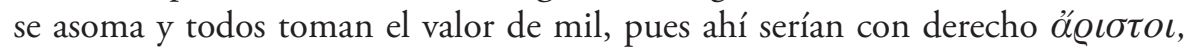
tan valorados por la "sana" soberbia de Heráclito, miles que ya no son parte de una mera masa incapaz de ver, una masa de hombres en estado de sopor, sino que son hombres como tales, conscientes de sí mismos y de lo que los rodea. El hombre así, inteligente en la consideración de Heráclito, lucha por su ciudad, puesto que resguarda la ley que la hace ser y que la fundamenta, la ley divina que comprende y según la cual vive ahora, en la comunidad que ella representa. Esta lucha es también un homólogo, como es obvio, del lógos. Si pensamos en el fragmento B8, donde Heráclito nos dice que todo surge según la lucha ( designar al lógos, puesto que todo acontece según el lógos, mostrándose como una eterna lucha de contrarios. En este sentido, hablar de "política del lógos" es hablar de una política inteligente, pero no una política de políticos, entendidos en su sentido actual, sino una política de hombres como seres políticos, una política del hacer del hombre que vive en armonía, es decir, que vive en el conflicto que es lo propio de su naturaleza, y por tanto de la naturaleza misma tanto como de la naturaleza social que el propio hombre crea, porque sabe que de aquél, del conflicto constante, surge la armonía.

Esta forma de entender la política muestra al hombre como dejándose llevar por el río, río que es la propia naturaleza, el lógos, la ley divina, y fluir con él, es decir, entrar en el devenir del cosmos y con ello, afrontar de cara las crisis que constituyen el paso incial hacia el nuevo ciclo de tensiones, inacabables y naturales, obedeciendo así la voluntad de lo uno, o sea, del lógos. Para el orden político de la sociedad, en todo caso, no se trataría simplemente de mantener la eterna lucha, sino que se trataría de sospechar de todo intento de regularidad y con ello, todo intento conservador de proteger lo que hace tiempo ha quedado en el pasado. El cambio es lo único constante en el mundo y hay que ajustarse a él, leyendo claramente los indicadores del propio tiempo, como hizo Heráclito al manifestar su desacuerdo sobre la expulsión de Hermodoro de Éfeso, o bien mostrándose contrario a la simplonería y facilidad con la que vivían las clases opulentas de 
su ciudad. Se trataría, pues, la política de Heráclito, de un intento de perpetuar aquello único que puede conservarse: el conflicto y la transformación, pero no a secas, puesto que esto sería ser sumiso respecto del dvenir del mundo, cosa que ni el mismo Heráclito hizo, sino que más bien se trata de una exhortación a dos cosas primordiales, a saber: a conocerse a sí mismos, para conocer la propia naturaleza y descubrir ahí lo común y, luego de ello, como segundo elemento esencial de la exhortación heraclítea, ser inteligentes, es decir, como en B114 se dice, fortalecerse con lo común. El sí mismo y lo común (el lógos) como punto de partida y de llegada, respectivamente, del pensar político de Heráclito.

\section{Bibliografía}

Bisé, Pierre, (1925) La politique d'Héraclite d'Éphèse. Alcan, Paris.

Bremmer, Jan, (1994) Greek Religion, Oxford UP, Oxford.

Bywater, I., (1877) Heracliti Epheseii Reliquiae. E Typographeo Clarendoniano, Oxonii.

Caballero, Raúl, (2008) "Las musas jonias aprenden a escribir: ley escrita y tratado en prosa en los milesios y Heráclito”, Emerita, v. 76, n 1, pp. 1-33. , (2012 a) "El juego de la ficción en las Epistolas pseudo-heracliteas: entre la verosimilitud histórica y la leyenda biográfica” en Martínez, J. (ed.) Mundus vult decipi. Estudios interdisciplinares sobre falsificación textual y literaria. Ediciones Clásicas, Madrid

, (2012 b) "La lucha del pueblo por la ley: una nueva propuesta de Lectura del fragmento 22 B 44 DK de Heráclito" en Exemplaria classica: journal of classical philology, №. 16, 2012 , págs. 3-16.

, (2012 c) Recensión de: HÉRACLITE D'ÉPHĖSE, Heraclitea IV. La reconstruction. A. Le livre "Les Muses» ou "De la Nature». Texte reconstruit à partir des fragments (III.3.B) et des opinions (III.2), traduit et annoté par SERGE N. MOURAVIEV, Academia Verlag, Sankt Augustin, 2011. Incluye la traducción del texto en francés de la reconstrucción de Mouraviev, en Exemplaria classica: journal of classical philology, №. 16, 2012 , págs. 177202.

Capelle, W., (1981) Historia de la filosofía griega. Trad. Emilio Lledó, Gredos, Madrid, $1^{\circ}$ ed. W. de Gruyter, Berlín, 1954. 
Cappelletti, Ángel., (1960) Epistolas Pseudo-Heracliteas. Universidad Nacional del Litoral, Rosario. Zulia.

(1974) Diógenes de Apolonia y la segunda filosofía jónica. Universidad del

Capizzi, A., (1979) Eraclito e la sua leggenda. Proposta di una diversa lettura dei frammenti. Dell'Ateneo \& Bizzari, Roma.

Chantraine, Pierre, (1968) Dictionnaire ètymologique de la langue grecque. Histoire des mots. Klincksieck, Paris.

Colli, G., (2010) La sabiduría griega III: Heráclito. Trad. Dionisio Mínguez, Trotta, Madrid ( $1^{\circ}$ ed., 1980)

, (1988) La natura ama nascondersi. Adelphi, Milano.

Conche, Marcel, (1986) Héraclite: Fragments. PUF, Paris.

Fränkel, H., (2004²) Poesía y filosofía de la Grecia arcaica. A. Machado Libros S. A., Madrid, $2^{\circ}$ edición en español de la edición original en alemán: München, 1962.

Gigon, Olof, (1980) Orígenes de la filosofía griega, de Hesiodo a Parménides. Gredos, Madrid.

Guthrie, W. K. C., (1991) Historia de la filosofía griega I: los primeros presocráticos y los pitagóricos. Trad. de A. Medina González, Gredos, Madrid, $1^{\circ}$ ed., Cambidge University Press, 1962.

Heidegger, M., (1994) "Logos", en Conferencias y Artículos. Ediciones del Serbal, Barcelona.

Heidegger, M., \& Fink, E., (1986) Heráclito. Ariel, Barcelona, $1^{\circ}$ edición alemana de 1970.

Heródoto, Historia, v. III. Libros V-VI. Trad. Carlos Schrader, Gredos, Madrid, 2006.

JAEger, Werner, (1982) Alabanza de la ley: los origenes de la filosofía del derecho y los griegos. Centro de Estudios Constitucionales, Madrid, ( $1^{\circ}$ ed. en inglés de 1947). , (2003) La teología de los primeros filósofos griegos. FCE, México D. F., (1º reimp.).

, (2006) Paideia, los ideales de la cultura griega. FCE, México D. F., $2^{\circ}$ ed., (18 reimp.)

Kahn, CH., (1979) The Art and Thought of Heraclitus. Cambridge University Press, London. 
KIrK, G. S., (1975) Heraclitus, the cosmic fragments. Cambridge University Press, Great Britain.

Kirk, G. S., Raven, J. E. y Schofield, M., (1987) Los filósofos presocráticos. Gredos, Madrid, $2^{\circ}$ ed.

Kostas, A., (1962) Héraclite et la philosophie. Éditions de Minuit, Paris.

Laercio, Diógenes, Vidas de los filósofos ilustres. Trad. Carlos García Gual, Alianza, Madrid, 2007.

Mansfeld, J., (2008) Die Vorsokratiker I. Philipp Reclam, Stuttgart, (1 ed. 1983)

Marcovich, Miroslav, $\left(2001^{2}\right)$ Heraclitus, greek text with a short commentary (Editio Maior). Academia Verlag, Sankt Agustin, (Edición aumentada de la $1^{\circ}$ ed. Marcovich, M, Heraclitus, greek text with a short commentary. U. Andes, Mérida, Venezuela, 1967.)

, (1968) Heraclitus: texto griego y versión castellana (Editio Minor). Talleres Gráficos Universitarios, Mérida.

Mazzarino, S., $\left(2007^{3}\right)$ Fra oriente e occidente. Ricerche di storia greca arcaica. Bollati Boringhieri, Torino (1947 , Florencia; $1989^{2}$, Milán)

Mondolfo, Rodolfo, (2007) Heráclito: textos y problemas de su interpretación. S. XXI, México D. F., (13 ed.).

Mouraviev, S., (2013) "Editing Heraclitus (1999-2012): Ten Volumes Plus One" en Epoché, Volume 17, Issue 2 (Spring 2013).

Rivera, J. E., (2006) Heráclito el esplendente. Brickle Ediciones, Santiago.

Thomas, Rosalind, (1992) Litteracy and Orality in Ancient Greece. Cambridge, Nueva York-Melbourne. 